\title{
Evaluation of the hepato-renal functions and antimicrobial activity of fatty amido benzoic acid synthesised from Citrullus colocynthis seed oil
}

\author{
Adewale Adewuyi ${ }^{*}$, Chiagoziem A. Otuechere ${ }^{2}$, Nkechi H. Ellah ${ }^{1}$, Shiva Shanker Kaki ${ }^{3}$, Scott O. Fayemi \\ and Charles B. Adeosun ${ }^{1}$
}

\begin{abstract}
Rapid progression in resistance to antimicrobial agents by pathogenic organisms is a serious concern. This study aimed to synthesize fatty amido benzoic acid (FBA) from Citrullus colocynthis seed oil (CCO) and evaluate its safety profile as an alternative bioactive agent for combating drug-resistant pathogens. FBA was synthesised through simple chemical reaction route and examined for its antioxidant activity and antimicrobial capacity against selected drugresistant microorganisms. Effect of FBA on hepato-renal function makers and oxidative stress was also examined using Wistar rats. Density functional theory (DFT) approach was employed to understand the action of FBA with the aid of lowest unoccupied molecular orbital (LUMO) and highest occupied molecular orbital (HOMO). Gas Chromatography (GC) revealed the most abundant fatty acid in CCO to be C18:2 (55.88\%). Results from Fourier transformed infrared spectroscopy (FTIR), and proton nuclear magnetic resonance ('HNMR) confirmed the synthesis of FBA with a yield of 97.10\%. FBA exhibited antioxidant potential $\left(I_{50}\right.$ of $\left.1.96 \mu \mathrm{g} \mathrm{mL}^{-1}\right)$ as well as antimicrobial potency. Minimum inhibitory concentration (MIC) of FBA was $0.026 \mathrm{mg} \mathrm{mL}^{-1}$. Biochemical parameters such as alanine aminotransferase (ALT), aspartate aminotransferase (AST), creatinine, hydrogen peroxide, and lipid peroxidation were significantly elevated in rats administered high dose FBA $\left(100 \mathrm{mg} \mathrm{kg}^{-1}\right)$. Histology of the liver and kidney confirmed the biochemical results. Furthermore, mechanism of action of FBA could be described by quantum chemical analysis to be via nucleophilic interaction, which may be viewed electronically as donor-acceptor interaction. The study presents FBA as a promising antimicrobial agent for combating drug-resistant pathogenic organisms.
\end{abstract}

Keywords: Antimicrobial activity, Antioxidant, Citrullus colocynthis, Drug-resistant pathogens, Fatty acid

\section{Introduction}

Resistance from pathogenic organisms is a big concern, as most known drugs are losing efficacy against disease control and management [1]. The risk of abandoning previously efficient drugs is becoming alarming due to side effects or recurrence of the disease. It has become

\footnotetext{
*Correspondence: walexy62@yahoo.com

${ }^{1}$ Department of Chemical Sciences, Faculty of Natural Sciences,

Redeemer's University, Ede, Osun State, Nigeria

Full list of author information is available at the end of the article
}

evident that bacteria possess the genetic ability to acquire and transmit resistance to drugs. This ability to transmit resistance is a major concern in most nations of the world. Inappropriate handling of antibiotics in the treatment of animal disease and in agricultural practice has contributed to the widespread of drug-resistant pathogenic organisms. Apart from the loss of drug efficacy, a new dimension to this problem is the re-emergence of chronic diseases, which are difficult to tackle. Overtime, pathogenic organisms are developing resistance against most known drugs used in disease control. This 
has necessitated the need to develop new drugs that can serve as a replacement for these drugs.

Most known drugs in the market were produced from synthetic chemicals. Some of which have their negative effect when they get into the environment such as soil and water. Apart from the drug-resistant problem, these synthetic drugs are becoming expensive due to the cost of production of fine chemicals required for their development. Previous studies have shown that the use of natural products or naturally sourced feedstocks in the control and management of diseases caused by pathogenic organisms have merits over drugs derived from synthetic sources [2]. A good example of such naturally sourced feedstock is the use of plant seed oil as starting material for the production of bioactive agents that can serve as an alternative for combating drug-resistant pathogenic organisms.

Plant seed oils are rich in fatty acids, which are present in varying amounts. Due to their composition and related properties, they are potential resources in the development of pharmaceutical agents [3, 4]. Moreover, they are from a renewable source, cheap, non-toxic, and environmentally friendly, which makes them better when compared with the ones sourced from synthetic chemicals. They have been reported to exhibit bioactive properties [4-6]. However, the exhibited bioactive properties can be improved by simple chemical modification, which places them at an advantage of probably having functions or properties, which are superior to those of already known pharmaceutical agents in the market. Seed oils are triglyceride, and several forms of chemical modification may be achieved by taking into account the ester bond and the possible unsaturated bonds present in the carbon chain length. Previous studies have reported various types of modification, which included; pyrolysis, amidation, transesterification, epoxidation, acetylation, hydrogenation, sulphonation, alkoxylation, and oxidation [7-9]. However, chemical modification of seed oil is a sustainable and promising route to developing an alternative to combating drug-resistant pathogenic microorganisms. Interestingly, this study aims to modify oil from the seed of Citrullus colocynthis as an alternative means of combating drug-resistant pathogens. This work proposes the modification of $\mathrm{CCO}$ via amidation using 4-amino benzoic acid in the presence of sodium methoxide as a catalyst.

Citrullus colocynthis belongs to the Cucurbitaceae plant family. It is a good source of oil, which is underutilized. Evaluating the potentials of using $\mathrm{CCO}$ as an alternative for treating disease-causing pathogens will be a viable way of finding useful applications for CCO. Despite the potential of natural resources being able to combat drug-resistant pathogens, it is important to evaluate the safety profile of these natural resources. Moreover, their capacity to combat disease-causing pathogens does not mean that they are not toxic to the human biological system. This has necessitated the need to screen the proposed new product (FBA) for its safety profile. The goal of the study is to synthesis FBA as an antimicrobial agent from $\mathrm{CCO}$ and also check whether it is toxic by evaluating its effect on rat organs. Therefore, the present study is focused on the synthesis and safety profile of FBA from $\mathrm{CCO}$ as an alternative bioactive agent for combating drug-resistant pathogens.

\section{Materials and methods Materials}

Citrullus colocynthis seeds were purchased from Ede market, Osun state, Nigeria. They were ground into powder. Oil was extracted from the ground seed in a soxhlet extractor for $10 \mathrm{~h}$ using n-hexane [10]. Ethylacetate, n-hexane, sodium sulphate, potassium hydroxide, sulphuric acid, methanol, potassium chloride, 2,2-diphenyl1-picrylhydrazyl, 1-chloro-2, 4-di nitrobenzene (CDNB), sodium chloride, thiobarbituric acid (TBA), epinephrine, 5',5'- Dithiobis-2-nitrobenzoic acid (DTNB), and dimethylsulphoxide (DMSO) were purchased from Sigma Chemical Company (USA). All other chemicals used were of analytical grade and were obtained from Sigma-Aldrich, St. Louis, USA.

\section{Fatty acid composition}

CCO was analyzed for its fatty acid composition, as previously described [11]. Briefly, the oil was transesterified using $2 \%$ sulphuric acid in methanol reagent. The methyl esters obtained were extracted with ethylacetate, washed with distilled water until free of acid and dried over anhydrous sodium sulphate. Ethylacetate was removed on a rotary evaporator and finally analyzed using GC. For the GC analysis, an Agilent 6850 series GC equipped with an FID detector was used. To achieve this, a DB-225 capillary column was used; a column temperature of $160{ }^{\circ} \mathrm{C}$ was held for $2 \mathrm{~min}$; this was gradually increased to $230^{\circ} \mathrm{C}$ at $4{ }^{\circ} \mathrm{C} \mathrm{min}{ }^{-1}$ and finally maintained at $230^{\circ} \mathrm{C}$ for $10 \mathrm{~min}$. The detector $\left(250^{\circ} \mathrm{C}\right)$ and injector $\left(230^{\circ} \mathrm{C}\right)$ temperatures were also regulated at a split ratio of 50:1 using nitrogen as the carrier gas at a flow rate of $1.5 \mathrm{~mL} \mathrm{~min}^{-1}$.

\section{Synthesis of FBA}

$\mathrm{CCO}$ was first transesterified using $1 \% \mathrm{KOH}$ in methanol, which was refluxed for $3 \mathrm{~h}$ at $70{ }^{\circ} \mathrm{C}$. The mixture of methyl esters obtained was extracted with ethylacetate, washed with distilled water until free of $\mathrm{KOH}$, and dried over sodium sulphate. Ethylacetate was removed using a rotary evaporator. The methyl esters $(0.05 \mathrm{~mol})$ were reacted with 4 -amino benzoic acid $(0.08 \mathrm{~mol})$ in 
the presence of sodium methoxide $(0.5 \% \mathrm{wt} / \mathrm{wt})$ in a two-necked round bottom flask, which was refluxed for $3 \mathrm{~h}$ at $70{ }^{\circ} \mathrm{C}$. At the end of the reaction, the mixture obtained was extracted with ethylacetate, washed with distilled water until neutral to litmus paper, and passed over sodium sulphate. The ethylacetate was removed on a rotary evaporator, which gave rise to a product yield of $97.10 \%$. The scheme for the synthesis is shown in Fig. 1.

\section{Characterization of CCO and FBA}

$\mathrm{CCO}$ and FBA were evaluated for their functional groups' composition using FTIR (FTIR, Perkin Elmer, spectrum RXI $83,303, \mathrm{MA}$, USA) in the range of $400-4500 \mathrm{~cm}^{-1}$ while the ${ }^{1} \mathrm{HNMR}$ analysis was achieved on a $400 \mathrm{MHz}$ Bruker NMR spectrophotometer in chloroform containing TMS as an internal standard.

\section{Antioxidant activity assay}

FBA was evaluated for its antioxidant capacity by determining its DPPH free radical scavenging ability spectrophotometrically as previously reported [12]. Briefly,
DPPH stock solution $(12.5 \mathrm{mg}$ in $50 \mathrm{~mL}$ of methanol) was prepared and kept in the dark cupboard. Concentrations of FBA ranging from $50-100 \mu \mathrm{g} \mathrm{mL}^{-1}$ were prepared using methanol as a solvent in a volumetric flask. To each of these concentrates DPPH $(1 \mathrm{~mL})$ was added. They were incubated for $30 \mathrm{~min}$ at $37^{\circ} \mathrm{C}$ in the dark, and the absorbance read at $517 \mathrm{~nm}$. The standard (Vit C) and blank were subjected to the same conditions, and absorbance read at $517 \mathrm{~nm}$. The experiment was conducted in triplicate. Antioxidant capacity of FBA was calculated as:

$$
\begin{gathered}
Q(\%)=\frac{\text { Absorbance of control }- \text { Absorbance of sample }}{\text { Absorbance of control }} \\
\times 100
\end{gathered}
$$

\section{Antimicrobial screening}

Methicilin Resistant Staphylococcus aureus (MRSA) ATCC 71, Staphylococcus aureus ATCC 25923, E coli DMS 10974 and Pseudomonas aeruginosa ATCC 9027 were obtained from the Department of Biological<smiles>[R]C(=O)OC([2H])C(C)OC([R7])=O</smiles>

CCO<smiles>[R]C(=O)OC([R])([R])C([R])([R])OC</smiles>

Glycerol

Methyl esters<smiles>[R]C(=O)Nc1ccc(C(=O)O)cc1</smiles><smiles>[R]C(=O)Nc1ccc(C(=O)O)cc1</smiles><smiles>CO[N+]([O-])([O-])c1ccc(C(=O)O)cc1</smiles><smiles>[R7]C(=O)Nc1ccc(C(=O)O)cc1</smiles>

$F B A$

Fig. 1 Synthesis of FBA from CCO via simple chemical reaction 
Sciences, Redeemer's University. They were used in the antimicrobial susceptibility-testing assay in Mueller Hinton agar. Prior to the antimicrobial susceptibility assays, the test organisms were earlier cultured on nutrient agar and incubated at $37{ }^{\circ} \mathrm{C}$ for $24 \mathrm{~h}$. Cell density on their growth in peptone water was monitored in order to standardize them with the aid of a spectrophotometer at an optical density of 0.5 at $600 \mathrm{~nm}$ [13]. Wells $(6 \mathrm{~mm}$ in diameter) were bored in Mueller-Hinton agar plates, filled with FBA $(50 \mu \mathrm{L})$ at a concentration of $2.6 \times 10^{-}$ ${ }^{3} \mathrm{mg} \mathrm{L}^{-1}$, inoculated with bacterial strains under aseptic condition and incubated at $37^{\circ} \mathrm{C}$ for $24 \mathrm{~h}$. Water (solvent for FBA) was the blank. The zone of inhibition was measured after the incubation.

\section{Determination of MIC}

The MIC value of FBA was established as the lowest concentration that completely inhibited the growth of the test microorganisms after $48 \mathrm{~h}$ of incubation at $37{ }^{\circ} \mathrm{C}$. Microbes were transferred into the sterile nutrient broth, and with the help of hemocytometer; standard cells were adjusted to $1 \times 10^{-6}$ cell $\mathrm{mL}^{-1}$. The standardized culture was pipetted $(1 \mathrm{~mL})$ and poured unto readily prepared plate of Mueller-Hinton agar. Wells $(6 \mathrm{~mm}$ diameter) were bored and filled with FBA $(50 \mu \mathrm{L})$ of aqueous concentrations (ranging from $2 \times 10^{-7}$ to $2 \times 10^{3} \mu \mathrm{g} \mathrm{mL}^{-1}$ ).

\section{Quantum chemical parameters}

FBA was subjected to electronic structure modeling. All theoretical calculations were performed using the DFT electronic structure programs at B3LYP/6-31G level theory using Spartan 14.1 software [14]. This also included the distribution of frontier molecular orbitals in order to establish the reactivity and active site of FBA for the antioxidant, antimicrobial, and toxicity processes.

\section{Animals and treatment}

Healthy male rats were used for the experiments. Wistar rats weighing 150-200 g were used. The rats were randomly separated into 4 groups of 5 rats each, based on uniform average weight per group. They were housed on the following conditions: $12 \mathrm{~h}$ day/night cycle, temperature $25 \pm 2{ }^{\circ} \mathrm{C}$, relative humidity $(70-80 \%)$, and standard pelleted diet (Ladokun Feeds, Ibadan, Nigeria). All animals received humane care following guidelines governing the handling of laboratory animals as outlined by the Redeemer's University Committee on Ethics for Scientific Research.

Animals were treated as follows for 14 days:

- Group A: Control animal fed with 0.9\% saline

- Group B: Fed with FBA (10 $\mathrm{mg} \mathrm{kg}^{-1}$ body weight), orally, once, daily)
- Group C: Fed with FBA (50 $\mathrm{mg} \mathrm{kg}^{-1}$ body weight), orally, once, daily)

- Group D: Fed with FBA (100 $\mathrm{mg} \mathrm{kg}^{-1}$ body weight), orally, once, daily)

The different doses administered to the groups represent low, medium, and high doses as previously reported [15]. As the experiment proceeded, the animals were consistently examined on a daily basis for any clinical signs and symptoms of toxicity. After the 14th day, the Wistar rats were sacrificed by cervical dislocation $24 \mathrm{~h}$ after the last treatment. Blood samples were collected by a cardiac puncture; the blood samples were kept in clean EDTA bottles and centrifuged at $4000 \mathrm{~g}$ for $10 \mathrm{~min}$ (Heraeus Labofuge 300, Thermo Scientific, Hampshire UK). Plasma was carefully separated and stored frozen at $-20{ }^{\circ} \mathrm{C}$ until they were required for analysis. The liver and kidneys were carefully harvested and washed free of any extraneous materials. They were transferred into ice-cold 0.25 M sucrose solution, blotted with clean tissue paper and homogenized in phosphate buffer $(0.1 \mathrm{M}$, $\mathrm{pH}$ 7.4). Homogenates were centrifuged at $10,000 \mathrm{~g}$ for 20 min at $4{ }^{\circ} \mathrm{C}$ to obtain the post mitochondrial fraction. Subsequently, the supernatant was collected and stored frozen at $-20{ }^{\circ} \mathrm{C}$ until they were required for analysis. Biochemical indices were measured in samples using a spectrophotometer (Bibby Scientific Jenway 7305 UV, $\mathrm{UK})$.

\section{Estimation of somatic index}

Since exposure to chemicals may result in bioaccumulation in the body tissues, the exposure of Wistar rats to FBA was expressed as renatosomatic index (RSI) and hepatosomatic index (HSI). The liver and kidney harvested from both test and control animals were blotdried using an absorbent filter paper. The organosomatic index (OSI) was calculated as previously described [16]:

$$
\text { OSI }=\frac{\text { Weight of } \operatorname{organ}(g)}{\text { Body weight }(g)} X 100
$$

\section{Biochemical assays}

Biochemical markers were determined by checking plasma concentrations of alanine aminotransferase, aspartate aminotransferase, albumin, total bilirubin, urea, creatinine, potassium, and sodium using diagnostic kits as reported in a previous study [17]. Catalase (CAT) was determined as described by Luke [18] while hydrogen peroxide and malondialdehyde (MDA) levels were determined based on ferrous oxidation with xylenol orange and measurement of thiobarbituric acid reactive 
substances, respectively, in hepatic and renal tissues [19, 20].

\section{Histopathology}

The kidney and liver tissues of the animals were fixed in $10 \%$ formaldehyde, dehydrated in graded alcohol, and embedded in paraffin. The tissues were subsequently cut into $4-5 \mathrm{~mm}$ sections by a microtome, fixed on the slides, and stained with hematoxylin and eosin for light microscopic analyses.

\section{Statistical analyses}

All data were expressed as mean \pm standard error of mean. Differences between the groups were determined by one-way analysis of variance (ANOVA), and post hoc testing was performed using Dunnet's multiple comparison tests (Graph Pad Prism software, Inc., San Diego, CA). Values were regarded as significantly different at $p<0.05$.

\section{Results}

\section{Synthesis and characterization}

A golden yellow oil with a percentage yield of 54.51 was obtained, and the fatty acid composition is presented in Table 1. The most abundant fatty acid in the oil is C18:2 (55.88\%), while the least is C14:0 (0.07\%). The results of the fatty acid revealed the presence of long-chain fatty acids (C20-C24) in small amount in the oil. Other physicochemical characterization of CCO may be achieved by classical method of analysis. The unsaturation of the oil was found to be $78.28 \%$, while the saturation level was $21.72 \%$. The FTIR results of the CCO and FBA are presented in Fig. 2. The spectra shows bands corresponding

\section{Table 1 Fatty acid composition of CCO}

\begin{tabular}{lc}
\hline Fatty acid & Composition (\%) \\
\hline C14:0 & 0.07 \\
C14:1 & 0.32 \\
C16:0 & 11.18 \\
C16:1 & 0.12 \\
C18:0 & 9.76 \\
C18:1 & 17.10 \\
C18:2 & 55.88 \\
C18:3 & 4.46 \\
C20:0 & 0.32 \\
C20:1 & 0.08 \\
C22:0 & 0.10 \\
C24:0 & 0.29 \\
C24:1 & 0.32 \\
Unsaturation & 78.28 \\
Saturation & 21.72 \\
\hline
\end{tabular}

to the different functional groups in $\mathrm{CCO}$ and $\mathrm{FBA}$. The FTIR spectra of $\mathrm{CCO}$ and FBA revealed bands at $3010 \mathrm{~cm}^{-1}$, which were attributed to the unsaturation groups $(-\mathrm{C}=\mathrm{C}-)$ present in both $\mathrm{CCO}$ and $\mathrm{FBA}$. The bands at 2930 and $2855 \mathrm{~cm}^{-1}$ were assigned to the vibrational frequencies of alkane, which are the methyl $\left(-\mathrm{CH}_{3}-\right)$ and methylene $\left(-\mathrm{CH}_{2}-\right)$ groups, respectively. The vibrational frequency for the ester functional group was found at $1742 \mathrm{~cm}^{-1}$ in $\mathrm{CCO}$, but this vibrational frequency disappeared in FBA with the appearance of a new band at $1625 \mathrm{~cm}^{-1}$. This new band at $1625 \mathrm{~cm}^{-1}$ was assigned to be the vibrational frequency of an amide functional group suggesting the synthesis of FBA. Furthermore, a new band also appeared at $3342 \mathrm{~cm}^{-1}$ in FBA, which was not found in CCO. This band also corroborate the synthesis of $\mathrm{FBA}$, and it was considered the vibrational frequency of $\mathrm{N}-\mathrm{H}$ of amide. The ${ }^{1} \mathrm{HNMR}$ spectra are presented in Fig. 3. The spectra confirmed the synthesis of FBA. It reveals presence of methyl, methylene, and vinylic protons at $0.5-0.8,1-1.5$, and 2-2.4 ppm, respectively, in both CCO and FBA. The solvent peak appeared at $7.2 \mathrm{ppm}$ in both $\mathrm{CCO}$ and FBA. The unsaturation band which was seen in the FTIR at $3010 \mathrm{~cm}^{-1}$ appeared in the ${ }^{1} \mathrm{HNMR}$ spectra at $5.4 \mathrm{ppm}$ in both $\mathrm{CCO}$ and FBA, which confirms the presence of the unsaturated functional groups and also indicates that the double bonds were intact even during and after the reaction of $\mathrm{CCO}$ to produce FBA. The triglyceride backbone was seen at 4-4.3 ppm only in CCO, while the ester peaks appeared at $2.8 \mathrm{ppm}$. Both protons of the triglyceride backbone and ester groups disappeared in the spectrum of FBA. This disappearance is an indication that the ester functional groups were involved in the reaction suggesting the conversion of $\mathrm{CCO}$ to the product (FBA). However, new peaks at 3-3.3, 7.4, and 7.5 ppm emerged in FBA, which confirms the presence of carboxyl functional groups, aromatic protons, and amide functional groups in FBA. These new peaks confirm the formation of FBA.

\section{Antioxidant activity assay}

The antioxidant activity of FBA at different concentrations (ranging from $50-100 \mu \mathrm{g} \mathrm{mL}^{-1}$ ) was compared with that of vitamin $\mathrm{C}$, as presented in Fig. 4. However, the result revealed a higher $\mathrm{IC}_{50}$ for FBA $\left(1.96 \mu \mathrm{g} \mathrm{mL} \mathrm{m}^{-1}\right)$ than vitamin $C\left(40.20 \mu \mathrm{g} \mathrm{mL}^{-1}\right)$.

\section{Antimicrobial screening and MIC}

The antimicrobial capacity of FBA was evaluated by screening it against the growth of four organisms (MRSA ATCC 71, Staphylococcus aureus ATCC 25923, E coli DMS 10974 and Pseudomonas aeruginosa ATCC 9027), as shown in Table 2. The blank (water used as solvent for 

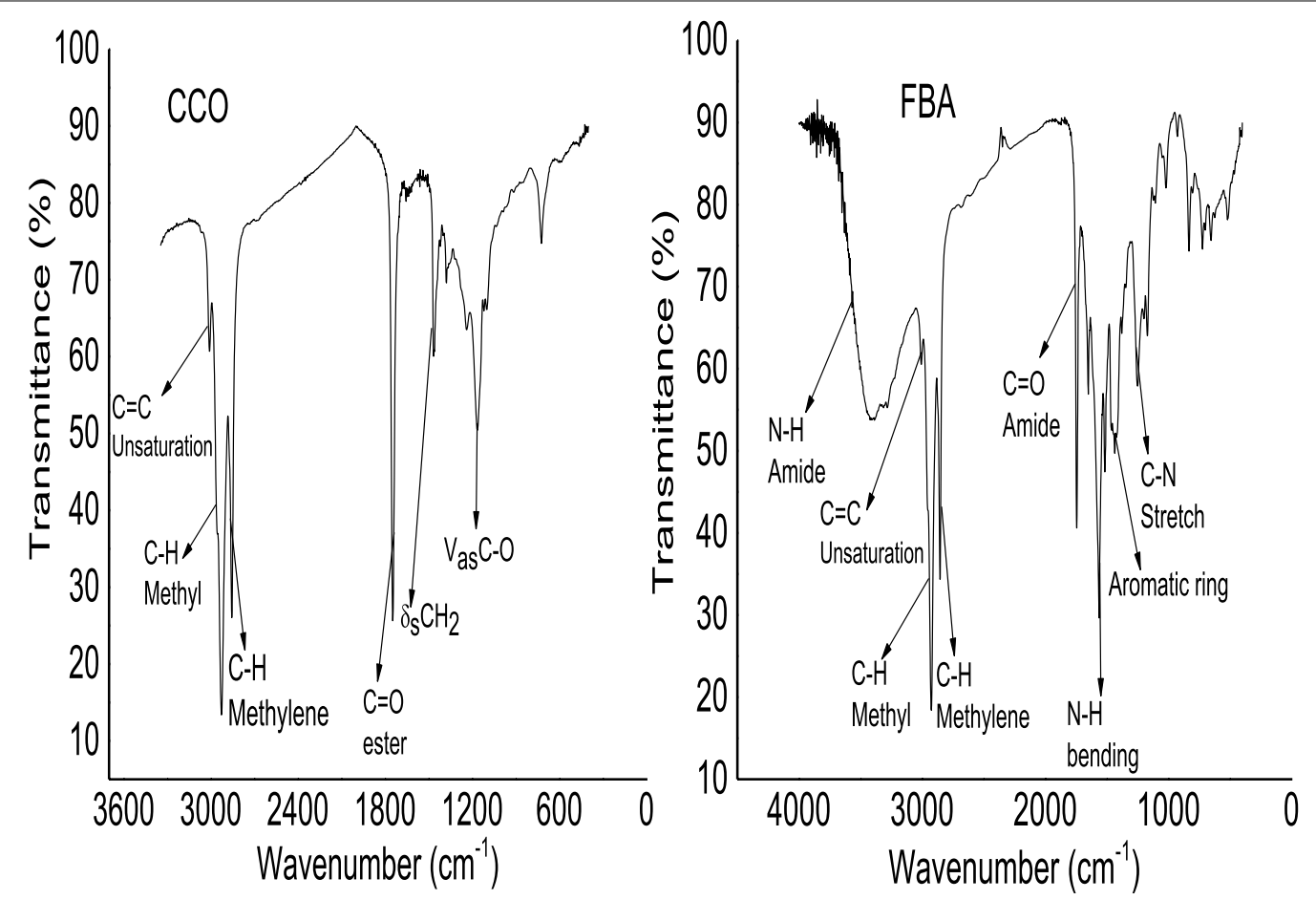

Fig. 2 FTIR spectra of CCO and FBA suggesting the presence of functional groups

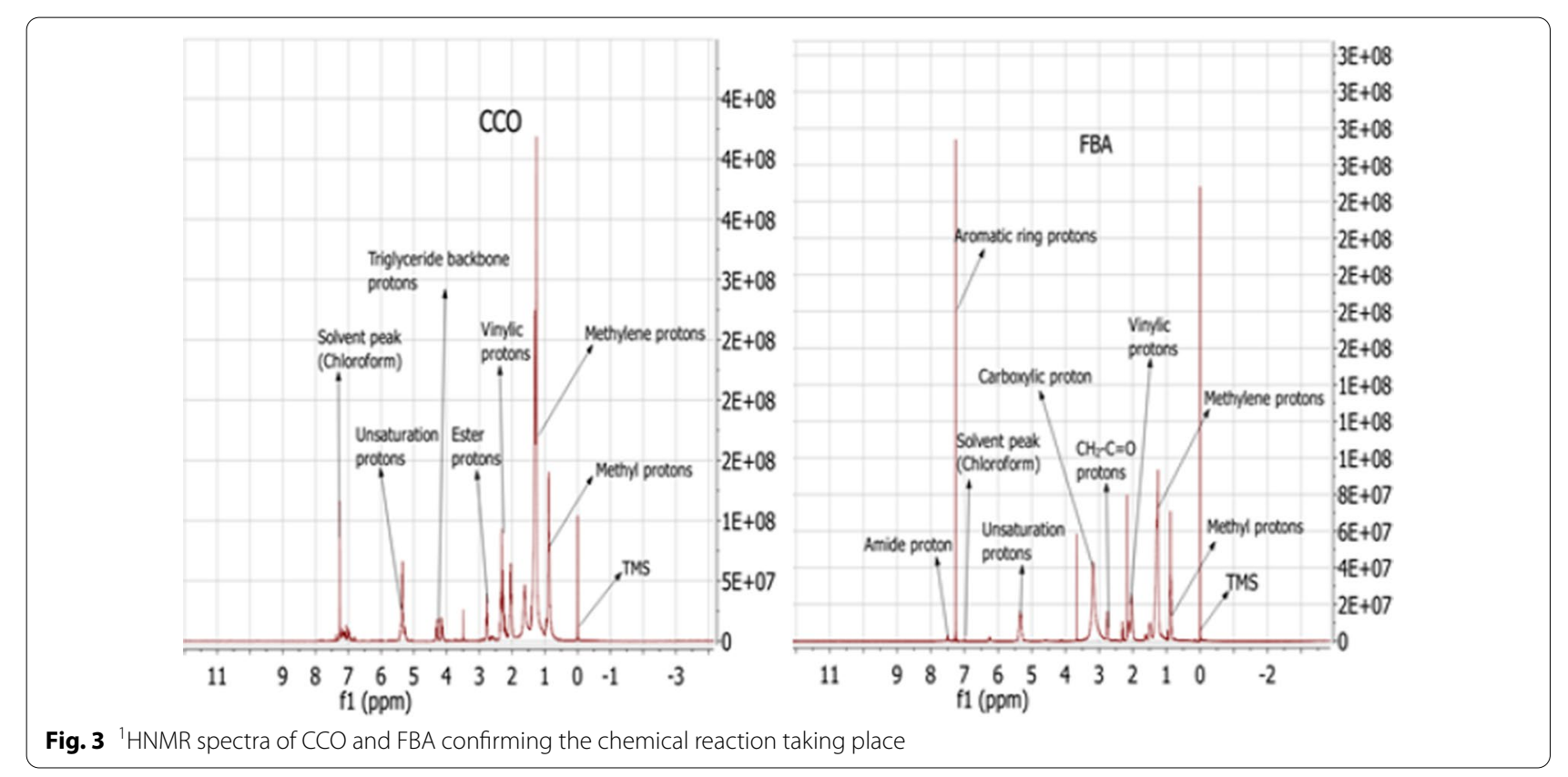

FBA) did not show any activity against the growth of the microorganisms. Among all the organisms studied, at a concentration of $2.6 \times 10^{-3} \mathrm{mg} \mathrm{L}^{-1}$, FBA had the highest inhibitory activity against Staphylococcus aureus ATCC 25923 , with a zone of inhibition of $17.67 \pm 2.50 \mathrm{~mm}$.
The lowest inhibitory activity was recorded against Pseudomonas aeruginosa ATCC 9027, with a zone of inhibition of $10.33 \pm 1.25 \mathrm{~mm}$. The MIC of FBA was compared with other reported plant-sourced antimicrobial agents, as shown in Table 3. The lower the MIC 


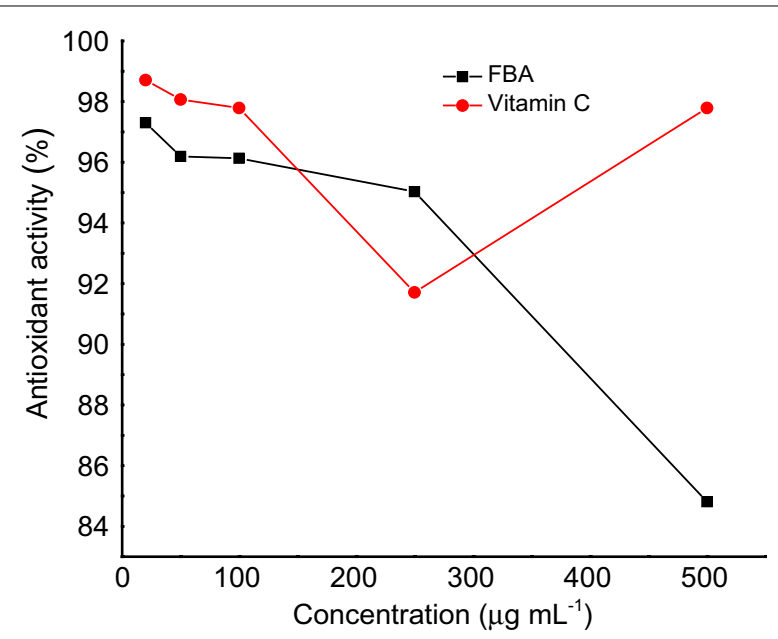

Fig. 4 Antioxidant activity of FBA and vitamin $\mathrm{C}$ at different concentration

Table 2 Antimicrobial screening of FBA

\begin{tabular}{ll}
\hline Organism & Inhibition $(\mathbf{m m})$ \\
\hline E.coli DMS 10974 & $12.67 \pm 1.70$ \\
MRSA ATCC 71 & $15.00 \pm 5.72$ \\
Pseudomonas aeruginosa ATCC 9027 & $10.33 \pm 1.25$ \\
Staphylococcus aureus ATCC 25923 & $17.67 \pm 2.50$ \\
\hline
\end{tabular}

value, the better the potency of such substance. The MIC of FBA was found to be $0.026 \mathrm{mg} \mathrm{mL}^{-1}$ for all the tested microorganisms.

\section{Estimation of somatic index}

The animals were examined throughout the feeding period and were found clinically normal and stable, with no physical defect or deterioration in locomotor performance. The results obtained for the bodyweight of the animals are presented in Table 4.

\section{Effect of FBA on biomarkers of hepato-renal damage}

In the screening of chemical compounds for pharmacological activities, it is important to test them for toxic characteristics. The acute toxicity study did not show any signs or symptoms of toxicity at the evaluated concentrations of FBA. There was no mortality recorded at the doses during the period of administration of FBA. The results obtained for the plasma clinical parameter after treatment for 14 days are presented in Table 5. There was no significant difference in AST activity between the control group and animals exposed to 10 and $50 \mathrm{mg} \mathrm{kg}^{-1}$ FBA, respectively. However, there was a significant difference in AST activity between the control group and the
$100 \mathrm{mg} \mathrm{kg}^{-1} \mathrm{FBA}$ administered rats $(\mathrm{p}<0.01)$. AST plays an important role in aminoacid metabolism, an increase in AST value in the $100 \mathrm{mg} \mathrm{kg}^{-1} \mathrm{FBA}$ administered rats might be indicative of a damage to the tissue. On the other hand, the ALT activity was significantly different across all treatment groups when compared with the control.

\section{Effect of FBA on the antioxidant defense system}

FBA was evaluated for its effect on the antioxidant defense system in rats. The results obtained are presented in Fig. 5. The liver catalase activity was significantly increased $(\mathrm{p}<0.01)$ across the test groups in comparison with the control group. However, in the kidney, a significant increase was only observed at the high dose FBA administration $\left(100 \mathrm{mg} \mathrm{kg}^{-1}\right)$.

\section{Histopathology}

The histopathology of the liver and kidney exposed to various doses of FBA are presented in Fig. 6. The liver and kidney of the control appeared normal, with no visible lesion while the test group showed mild congestion and periportal infiltration.

\section{Quantum chemical parameters and mechanism of action of FBA}

The exhibited antimicrobial activities of FBA may be attributed to two mechanisms as previously reported by Khameneh et al. [21], to include interference with vital components of microorganism and circumventing the conventional mechanisms of antibacterial resistance. It is obvious that by way of interference with a vital component of the microorganism, FBA may have targeted (I) cell-wall biosynthesis; (II) DNA replication and repair; (III) protein biosynthesis; (IV) cell membrane destruction; and (V) inhibition of a metabolic pathway. This mechanism was previously reported [21], as shown in Fig. 7. The electronic properties of FBA are shown in Fig. 8. This revealed the HOMO and LUMO density distribution, the ionization, and electrostatic potential. FBA exhibited some molecular properties, which are presented in Table 6 . The molecular surface area was found to be $198.52 \AA^{2}$, and dipole moment was 2.62 debye while solvation energy was $-36.42 \mathrm{~kJ} \mathrm{~mol}^{-1}$. The absolute hardness ( $\eta$ ) was calculated as:

$$
\eta=\frac{E_{L U M O}-E_{H O M O}}{2}
$$


Table 3 Comparison of the minimum inhibitory concentration of FBA with other antimicrobial agents in literature

\begin{tabular}{llllll}
\hline Sample & E.coli & Staphylococcus aureus & MRSA ATCC 71 & Pseudomonas aeruginosa & Reference \\
\hline MM & 62.5 & $7.8-62.5$ & - & $-7.8-31.25$ & {$[31]$} \\
AC & 6.24 & 6.24 & - & - & 3.2 \\
BV & 1.6 & 0.4 & - & 12.8 & {$[32]$} \\
CA & 12.8 & 1.6 & - & 2.00 & {$[33]$} \\
EC & 1.75 & 1.67 & - & 0.63 & {$[33]$} \\
ZM & 0.50 & 0.82 & 10.2 & 9.4 & {$[34]$} \\
LO & 13.4 & - & 11.8 & 9.4 & {$[34]$} \\
PG & ND & - & - & - & {$[35]$} \\
AV & 0.25 & 0.42 & - & 0.12 & {$[35]$} \\
HA & 0.51 & 0.25 & 0.026 & 0.026 & {$[36]$} \\
FBA & 0.026 & 0.026 & & & Present work \\
\hline
\end{tabular}

$-=$ Not determined

Values are in $\mathrm{mg} \mathrm{mL}^{-1}$

MM, Moringa oleifera methanol extract

AC, Annona crassiflora ethanolic extract

BV, Berberis vulgaris (Macerated Methanolic Extract)

CA, Cassia angustifolia (Macerated Methanolic Extract)

$E C$, Euclea crispa methanol extract

ZM, Ziziphus mucronata methanol extract

LO, Liquidambar orientalis Mill

PG, Punica granatum L.

AV, Aloe vera (Leaf Pulp Aqueous)

HA, Hypericum alpestre (methanol extract)

Table 4 Body weight, RSI and HSI of rats treated with FBA

\begin{tabular}{|c|c|c|c|}
\hline Treatment group & Body weight (g) & RSI (\%) & HSI (\%) \\
\hline Control & $252.10 \pm 1.29$ & 0.65 & 2.92 \\
\hline FBA (10 $\left.\mathrm{mg} \mathrm{kg}^{-1}\right)$ & $204.20 \pm 2.03^{* *}$ & 0.60 & 3.87 \\
\hline FBA (50 mg kg ${ }^{-1}$ ) & $197.90 \pm 0.41^{* *}$ & 0.57 & 3.10 \\
\hline FBA (100 $\left.\mathrm{mg} \mathrm{kg}^{-1}\right)$ & $195.00 \pm 1.00^{* *}$ & 0.53 & 2.31 \\
\hline
\end{tabular}

Data expressed as mean \pm SD for five rats per group. **Significantly different from control $(p<0.01)$

RSI, Renatosomatic index

HIS, Hepatosomatic index

\section{Discussion}

This observed antioxidant activity exhibited by FBA might be attributed to its ability to neutralize the free radical character of DPPH by transferring either hydrogen or electron to DPPH radical [22]; moreover, FBA contains heteroatoms with nonbonding electrons in its molecule. Interestingly, the activities of FBA against different strains of Staphylococcus aureus varied in this study. However, the use of plant-sourced remedy as antimicrobial agents has proved substantial [21, 23], which places the use of FBA as a potential source of antimicrobial agent for controlling the health challenges these pathogens may cause. The MIC obtained for E.coli
Table 5 Plasma clinical parameters in rats following 14 days treatment with FBA

\begin{tabular}{lcccc}
\hline Parameters & A & B & C & D \\
\hline AST, U/l & $104.8 \pm 6.1$ & $111.9 \pm 12.8$ & $104.8 \pm 8.1$ & $200.6 \pm 18.7^{* *}$ \\
ALT, U/l & $43.0 \pm 6.1$ & $72.1 \pm 3.4^{*}$ & $71.2 \pm 10.3^{*}$ & $84.7 \pm 3.4^{* *}$ \\
Total Bilirubin & $14.6 \pm 1.4$ & $14.6 \pm 1.2$ & $14.8 \pm 1.1$ & $17.5 \pm 1.1$ \\
Albumin, g/dl & $3.2 \pm 0.1$ & $1.6 \pm 0.1^{* *}$ & $3.1 \pm 0.1$ & $3.2 \pm 0.1$ \\
Creatinine, & $88.4 \pm 8.7$ & $100.8 \pm 8.8$ & $115.4 \pm 6.4$ & $118.1 \pm 6.9^{*}$ \\
$\quad \quad \quad$ mol/l & & & & \\
Urea, mmol/l & $0.7 \pm 0.02$ & $1.2 \pm 0.01^{* *}$ & $1.1 \pm 0.03^{* *}$ & $1.3 \pm 0.02^{* *}$ \\
Potassium, & $1.9 \pm 0.2$ & $2.5 \pm 0.2^{*}$ & $2.8 \pm 0.01^{* *}$ & $2.7 \pm 0.1^{* *}$ \\
$\quad$ mEq/l & & & & \\
Sodium, mEq/l & $140.7 \pm 2.8$ & $138.7 \pm 3.4$ & $140.1 \pm 3.1$ & $133.0 \pm 0.1$
\end{tabular}

Values are expressed as mean \pm SE for five rats in each group. A, Control; B, FBA $\left(10 \mathrm{mg} \mathrm{kg}^{-1}\right)$; C, FBA $\left(50 \mathrm{mg} \mathrm{kg}^{-1}\right)$; D, FBA (100 $\left.\mathrm{mg} \mathrm{kg}^{-1}\right)$; *significantly different from control $(p<0.05)$. **Significantly different from control $(p<0.01)$

$\left(0.026 \mathrm{mg} \mathrm{mL}^{-1}\right)$ is lower than values previously reported $[24,25]$. E.coli has also been associated with food poisoning [26]. Although synthetic chemicals from petrochemicals have been used in prevention and control of food poisoning disease caused by E.coli the repeated use of these chemicals resulted in accumulation of chemical residues in food and ultimately in human and animal, which has resulted in the emergence of microbial resistance 

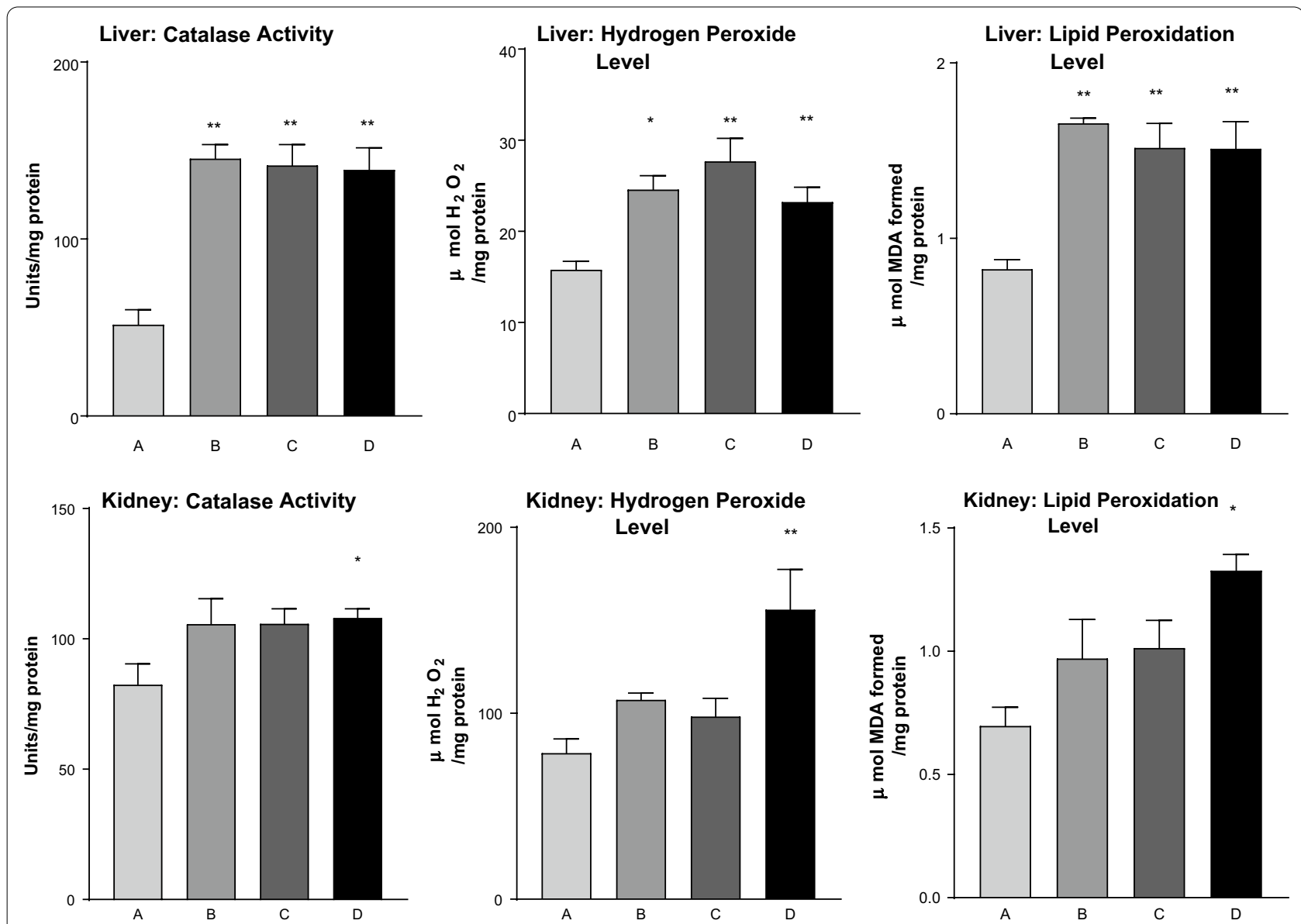

Fig. 5 Antioxidant enzyme activities and levels of lipid peroxidation following administration of FBA to rats for 14 consecutive days. Values are expressed as mean $\pm \mathrm{SE}$ for five rats in each group. $\mathrm{A}=$ Control; $\mathrm{B}=\mathrm{FBA}\left(10 \mathrm{mg} \mathrm{kg}^{-1}\right) ; \mathrm{C}=\mathrm{FBA}\left(50 \mathrm{mg} \mathrm{kg}^{-1}\right) ; \mathrm{D}=\mathrm{FBA}\left(100 \mathrm{mg} \mathrm{kg}^{-1}\right) ;{ }^{*}$ significantly different from control $(p<0.05)$. * Significantly different from control $(p<0.01)$

and unpleasant side effect of these synthetic chemicals [21-24]. The development of plant-sourced interventions was reported as a sustainable resource to overcome this challenge [27]. The MIC of an extract is considered to be good if the value is less than $0.1 \mathrm{mg} \mathrm{mL}^{-1}$; moderate if it is between 0.1 and $0.625 \mathrm{mg} \mathrm{mL}^{-1}$; and weak when it is above $0.625 \mathrm{mg} \mathrm{mL}^{-1}[24,28]$. Currently, the MIC of FBA was $0.026 \mathrm{mg} \mathrm{mL}^{-1}$ for all the studied microorganisms, which places FBA as a good antimicrobial agent.

The OSI was calculated for RSI and HSI. The value was found higher in HSI than RSI at the study doses (10-100 $\left.\mathrm{mg} \mathrm{kg}^{-1}\right)$. OSI, considered as the ratio of organs to body weight, could serve as an indicator of the presence of foreign bodies [29]. A previous study [30] showed HSI as an important biomarker due to the important role of the liver in detoxification. The values obtained for AST and ALT are higher than values obtained for the control groups. Although there was a slight increase in the total bilirubin level of rats administered with FBA $\left(100 \mathrm{mg} \mathrm{kg}^{-1}\right)$, there was no significant difference across all treatment groups when compared with the control group. The creatinine level increased across all test groups as the doses of FBA increased, but a significant difference $(p<0.05)$ was observed only at the dose of $100 \mathrm{mg} \mathrm{kg}^{-1} \mathrm{FBA}$ in comparison to the control group. Additionally, there was a significant elevation in the urea levels across all the test groups when compared with the control group. The potassium level increased significantly in all the test groups when compared with the control, whereas; there was no significant difference in sodium level when the test groups were compared with the control groups. The observed high catalase activity might indicate the ability of FBA to scavenge reactive oxygen species (ROS). It is plausible to suggest that FBA has a supportive defense against ROS. The hydrogen peroxide levels increased in both hepatic and renal tissues, especially at the $100 \mathrm{mg} \mathrm{kg}^{-1}$ treatment dose when compared with the control groups. In rats administered with FBA, hepatic MDA levels were significantly elevated at all treatment doses 


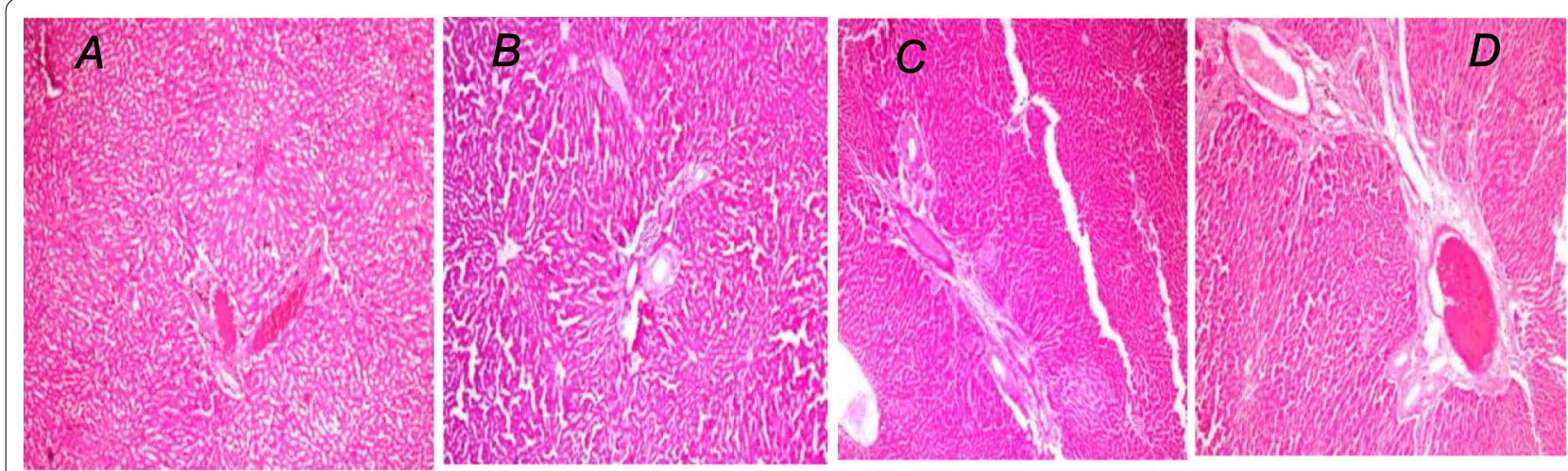

Photomicrograph of liver: A = Group A, B $=$ Group B, C = Group C, D = Group D
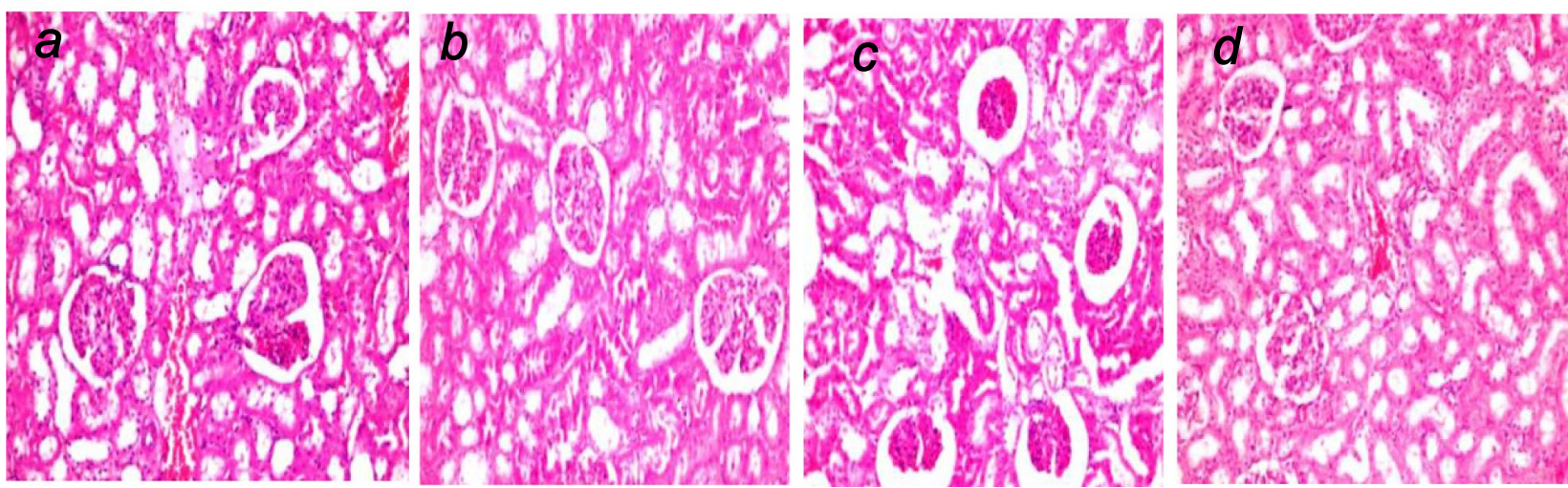

Photomicrograph of kidney: $a=$ Group A, $b=$ Group B, $c=$ Group C, $d=$ Group D

Fig. 6 Representative photomicrographs of liver and kidney of rats administered FBA

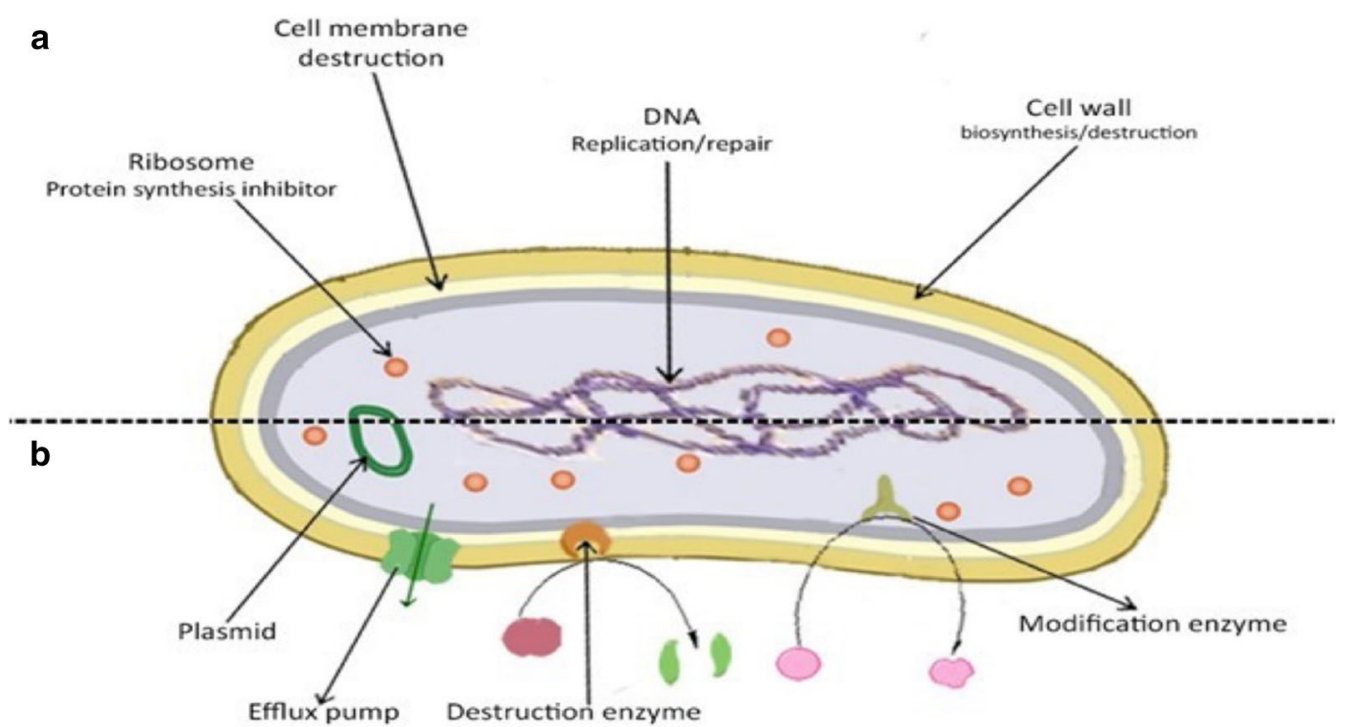

Fig. 7 Proposed mechanism of action of FBA: a Proven targets for antibacterial drugs; $\mathbf{b}$ Multiple antibiotic resistance mechanisms in bacteria (Khameneh et al. [21]) 


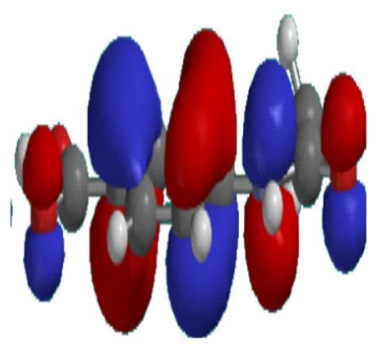

a

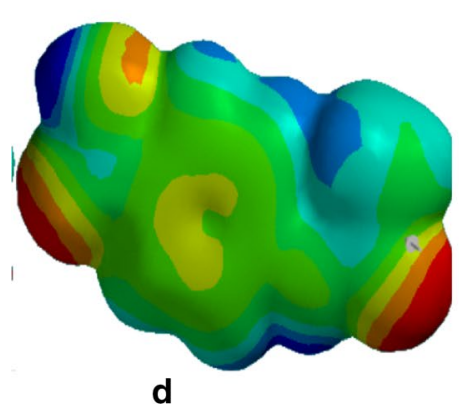

d

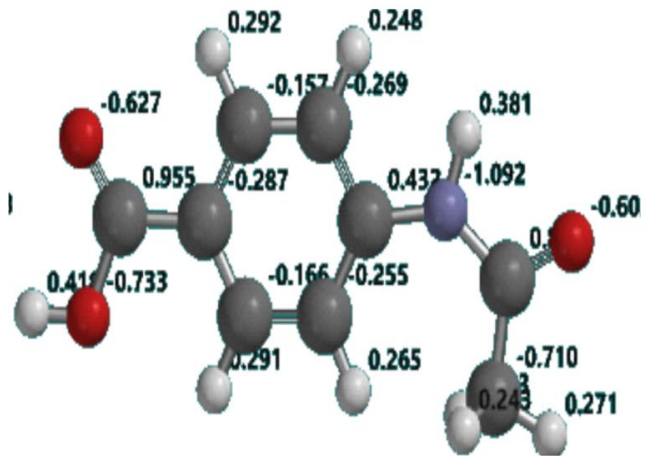

g

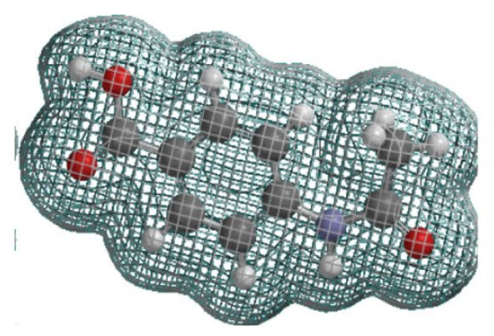

b

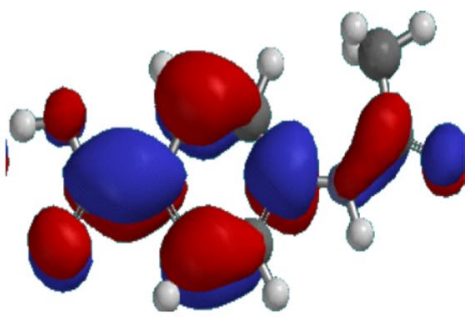

C

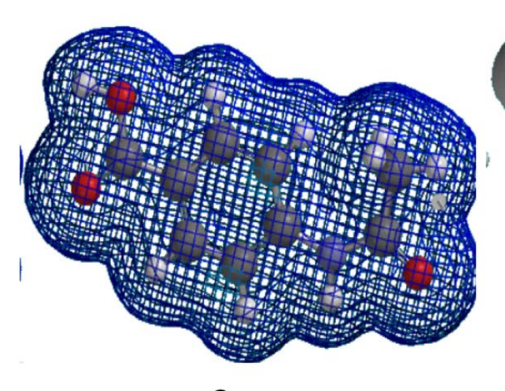

e

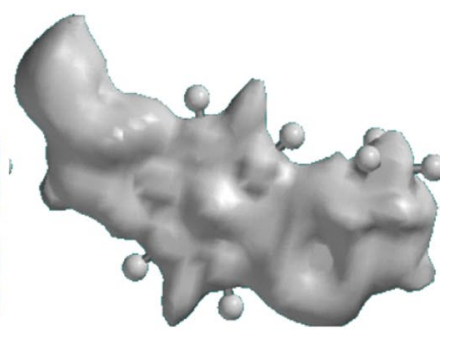

$\mathbf{f}$

Fig. 8 Electronic properties of FBA: HOMO density distribution of FBA (a); Electron density of FBA (b), LUMO density distribution of FBA (c), Electrostatic potential map of FBA (d), Local ionization potential map of FBA (e), Potential of FBA (f), Mulliken charge (g), Electrostatic charge (h)

\section{Table 6 Molecular properties of FBA}

\begin{tabular}{ll}
\hline Quantum chemical property & FBA \\
\hline Molecular surface area $\left(\AA^{2}\right)$ & 198.52 \\
Energy (au) & -621.65 \\
$E_{\text {HOMO }}(\mathrm{eV})$ & -8.85 \\
$E_{\text {LUMO }}(\mathrm{eV})$ & 2.38 \\
EUMO-HOMO $_{\text {LeV })}$ & 11.23 \\
Dipole moment (debye) & 2.62 \\
Solvation $(\mathrm{kJ} /$ mol) & -36.42 \\
Volume $\left(\AA^{3}\right)$ & 176.38 \\
Polarizability & 53.04 \\
Group & $\mathrm{Cs}$ \\
$\eta(\mathrm{eV})$ & 5.62 \\
\hline
\end{tabular}

when compared with the control group. Contrariwise, only the $100 \mathrm{mg} \mathrm{kg}^{-1} \mathrm{FBA}$ treatment group elicited a significant elevation in renal MDA levels. The observed elevation in hepato-renal MDA levels might imply an overwhelming influence of oxidative stress generated by FBA, which may have affected the antioxidant defense mechanism.

The photomicrograph of liver of rats in group $B$ (10 $\mathrm{mg} \mathrm{kg}^{-1} \mathrm{FBA}$ ) revealed mild congestion by inflammatory cells, while hepatic morphology of rats exposed to $50 \mathrm{mg} \mathrm{kg}^{-1} \mathrm{FBA}$ (group C) and $100 \mathrm{mg} \mathrm{kg}^{-1} \mathrm{FBA}$ (group D) presented with periportal infiltration by inflammatory cells and bile duct hyperplasia, respectively. Furthermore, renal histology of rats in group B showed hemorrhagic lesion and glomerular congestion; 


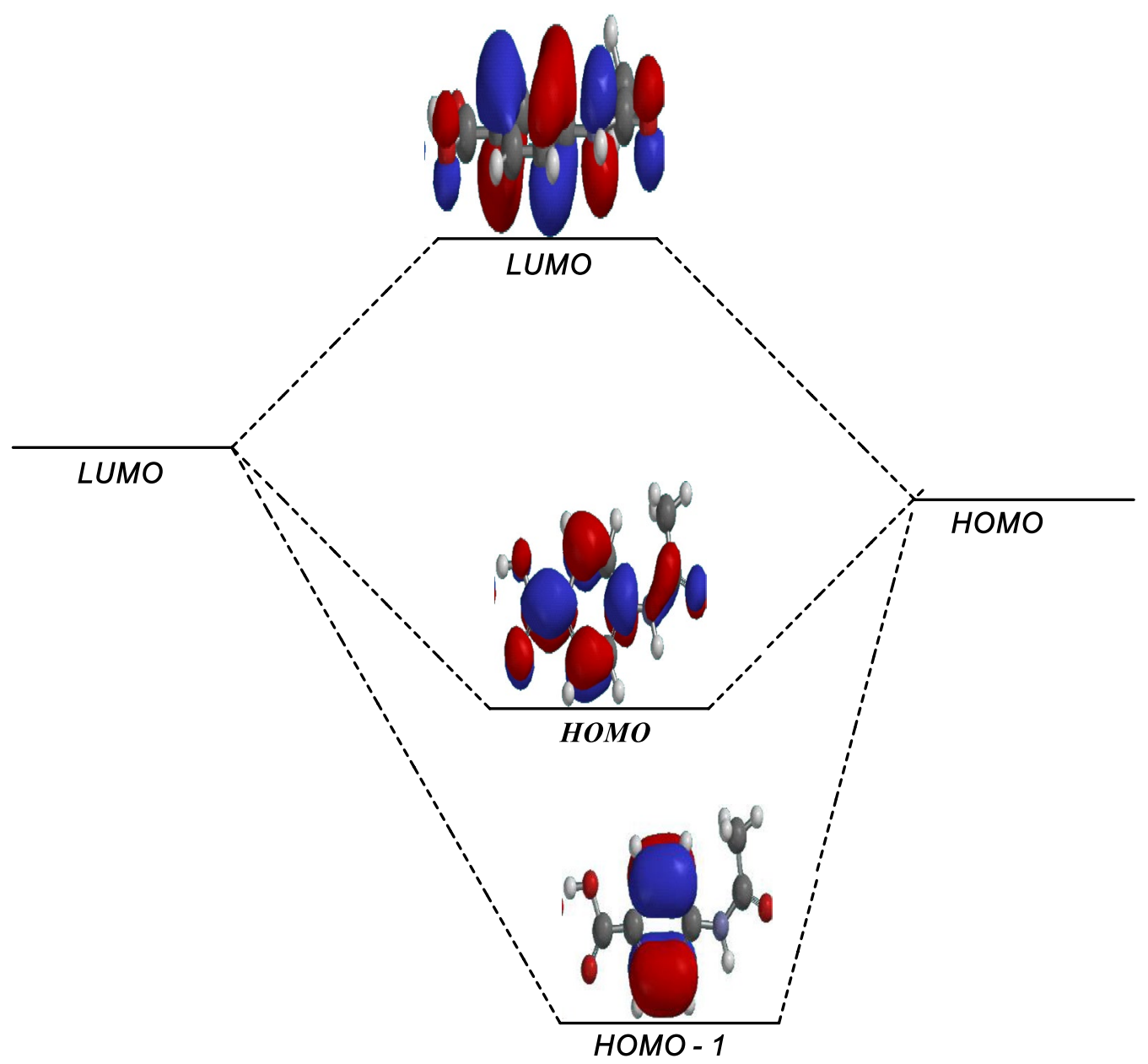

Fig. 9 Molecular orbitals of FBA indicating the transfer of nonbonding electrons for electronic interaction

group $C$ revealed fatty infiltration of tubules while group D had disseminated congestion and hemorrhagic lesion.

As previously reported by Khameneh et al. [21] shown in Fig. 7; the antibiotic resistance mechanism in bacterial; however, FBA must have circumvented these antibiotic resistance mechanisms in the tested organisms. FBA may have altered the outer membrane permeability in the test organisms and eventually destabilized them. The structure of FBA contains heteroatoms such as nitrogen and oxygen, which exhibited negative Mulliken charges as well as negative electrostatic charges. This negative charge is an indication that FBA may have exhibited nucleophilic character when screened against the microorganism as well as when administered to the Wistar rats. This nucleophilic character explains the possible interference with vital components of the microorganisms reported by Khameneh et al. [21]. This may be attributed to the congestion by inflammatory cells, hemorrhagic lesion, and glomerular congestion observed in the photomicrograph of the liver and kidney of rats studied (groups B to D). This interaction must have resulted in a distortion of the components of the pathogens, which explains the antimicrobial properties exhibited by FBA. This nucleophilic interaction of FBA with organs of the rats accounts for the toxic effect imposed by FBA. The nucleophilic interaction may be viewed electronically as a donor-acceptor interaction. Furthermore, Fig. 9 reveals the molecular orbital of FBA, which shows electronic delocalization over the heteroatoms in FBA.

\section{Acknowledgements}

Authors are grateful to the Department of Chemical Sciences, Redeemer's University for provision of research space and also appreciate support received from CSIR-Indian Institute of Chemical Technology, Hyderabad, India

\section{Authors' contributions}

$\mathrm{AA}, \mathrm{CAO}$ and NHE conducted the experimental studies such as extraction, synthesis, characterization and the animal studies. AA and CAO conceptualized, dsigned and directed the study. They also drafted the manuscript and wrote the first draft. SSK was involved in conducting the characterization such as NMR and fatty acid composition. SSK also wrote part of the manuscript and proof read. SOF conducted the antimicrobial studies and interpretation. CBA 
took part in the conceptualization and project development. All authors read and approved the final manuscript.

\section{Funding}

This research did not receive any specific grant from funding agencies in the public, commercial, or not-for-profit sectors.

\section{Availability of data and materials}

The data generated and used during the current study are available with the corresponding author on reasonable request.

\section{Ethics approval and consent to participate}

The study protocol was approved by the Redeemer's University Committee on Ethics for Scientific Research.

\section{Competing interests}

The authors have no conflicts of interest to declare.

\section{Author details}

1 Department of Chemical Sciences, Faculty of Natural Sciences, Redeemer's University, Ede, Osun State, Nigeria. ${ }^{2}$ Department of Biochemistry, Faculty of Basic Medical Sciences, Redeemer's University, Ede, Osun State, Nigeria. ${ }^{3}$ Centre for Lipid Science and Technology, CSIR-Indian Institute of Chemical Technology, Hyderabad 500007, India. ${ }^{4}$ Department of Biological Sciences, Faculty of Natural Sciences, Redeemer's University, Ede, Osun State, Nigeria.

Received: 6 July 2020 Accepted: 24 December 2020

Published online: 18 January 2021

\section{References}

1. Li B, Webster TJ (2018) Bacteria antibiotic resistance: New challenges and opportunities for implant-associated orthopaedic infections. J Orthop Res 36:22-32

2. Bonifácio BV, Ramos MAS, da Silva PB, Bauab TM (2014) Antimicrobial activity of natural products against Helicobacter pylori: a review. Annals Clin Microbiol Antimicrob 13:54

3. Beveridge THJ, Girard B, Kopp T, Drover JCG (2005) Yield and composition of grape seed oils extracted by supercritical carbon dioxide and petroleum ether: varietal effects. J Agric Food Chem 53:1799-1804

4. Mohamed HB, Duba KS, Fiori L, Abdelgawed H, Tlili I, Tounekti T, Zrig A (2016) Bioactive compounds and antioxidant activities of different grape (Vitis vinifera L.) seed oils extracted by supercritical $\mathrm{CO}_{2}$ and organic solvent. LWT Food Sci Technol 74:557-562

5. Lee CP, Yen GC (2006) Antioxidant activity and bioactive compounds of tea seed (Camellia oleifera Abel.) oil. J Agric Food Chem 54:779-784

6. Yoshime LT, de Melo ILP, Sattler JAG, de Carvalho EBT, Mancini-Filho J (2016) Bitter gourd (Momordica charantia L.) seed oil as a naturally rich source of bioactive compounds for nutraceutical purposes. Nutrire 41:12

7. Mubofu EB (2016) Castor oil as a potential renewable resource for the production of functional materials. Sustain Chem Process 4:11

8. Karmakar G, Ghosh P, Sharma BK (2017) Chemically modifying vegetable oils to prepare green lubricants. Lubricants 5:44

9. Rauf S, Jamil N, Tariq SA, Khan M, Kausar M, Kaya Y (2017) Progress in modification of sunflower oil to expand its industrial value. J Sci Food Agric 97:1997-2006

10. Adewuyi A, Oderinde RA, Rao BVSK, Prasad RBN (2012) Synthesis of alkanolamide: a nonionic surfactant from the oil of Gliricidia sepium. J Surfact Deter 15:89-96

11. Adewuyi A, Prasad RBN, Rao BVSK, Oderinde RA (2010) Oil composition, mineral nutrient and fatty acid distribution in the lipid classes of underutilized oils of Trilepisium madagascariense and Antiaris africana from Nigeria. Food Res Int 43:665-670

12. Atolani O, Omere J, Otuechere CA, Adewuyi A (2012) Antioxidant and cytotoxicity effect of seed oils from edible fruits. J acute dis 1:130-134

13. NCCLS (2005). National Committee for Clinical Laboratory Standards Methods for Dilution Antimicrobial Susceptibility Tests for Bacteria that Grow Aerobically: Approved standard (sixth ed.), National Committee for Clinical Laboratory Standards, Wayne. NCCLS
14. Adewuyi A, Oluwaseyifunmi A, Kaki SS, Oderinde RA (2019) Synthesis of fatty phenylthiosemicarbazide from underutilized Sesamum indicum seed oil: a promising corrosion inhibitor of carbon steel in developing country. SN Appl Sci 1:637

15. Adewuyi A, Otuechere CA, Adebayo OL, Anazodo C, Pereira FV (2018) Renal toxicological evaluations of sulphonated nanocellulose from Khaya sengalensis seed in Wistar rats. Chemico-Biol Inter 284:56-68

16. Merkle S, Hanke W (1988) Long-term starvation in Xenopus laevis daudinII. Effects on several organs. Comp Biochem Physiol A Comp Physiol 90:491-495

17. Otuechere CA, Madarikan G, Tinuala S, Bankole O, Osho A (2014) Virgin coconut oil protects against liver damage in albino rats challenged with the anti-folate combination, trimethoprim-sulfamethoxazole. J Basic Clin Physiol Pharmacol 25:249-253

18. Luck H (1974) In Bergmeyer J, Grabi M (Ed.) Catalase. In methods of enzymatic analysis. New York: Academic press

19. Wolff SP (1994) Ferrous ion oxidation in the presence of ferric ion indicator xylenol orange for measurement of hydroperoxides. Methods Enzymol 233:182-189

20. Varshney R, Kale RK (1990) Effect of calmodulin antagonist on radiation induced lipid peroxidation in microsomes. Int J Rad Biol 58:733-743

21. Khameneh B, Iranshahy M, Soheili V, Bazzaz BSF (2019) Review on plant antimicrobials: a mechanistic viewpoint. Antimicrob Resist Infect Control 8:118

22. Awah FM, Verla AW (2010) Antioxidant activity, nitric oxide scavenging activity and phenolic contents of Ocimum gratissimum leaf extract. J Med Plants Res 4:2479-2487

23. Abreu AC, McBainb AJ, Simoes M (2012) Plants as sources of new antimicrobials and resistance-modifying agents. Nat Prod Rep 29:1007-1021

24. Famuyide IM, Aro AO, Fasina FO, Eloff JN, McGaw LJ (2019) Antibacterial activity and mode of action of acetone crude leaf extracts of under-investigated Syzygium and Eugenia (Myrtaceae) species on multidrug resistant porcine diarrhoeagenic Escherichia coli. BMC Vet Res 15:162

25. Sibandze GF, van Zyl RL, van Vuuren SF (2010) The anti-diarrhoeal properties of Breonadia salicina, Syzygium cordatum and Ozoroa sphaerocarpa when used in combination in Swazi traditional medicine. J Ethnopharmacol 132:506-511

26. Pandey A, Singh P (2011) Antibacterial activity of Syzygium aromaticum (Clove) with metal ion effect against food borne pathogens. Asian J Plant Sci Res 1:69-68

27. Akinpelu DA, Aiyegoro OA, Akinpelu OF, Okah Al (2015) Stem bark extract and fraction of Persea americana (Mill) exhibits bactericidal activities against strains of Bacillus cereus associated with food poisoning. Molecules 20:416-429

28. Kuete V (2010) Potential of Cameroonian plants and derived products against microbial infections: a review. Planta Med 76:1479-1491

29. Giulio RT, Hinton DE (2008) The toxicology of fishes. CRC Press, Boca Paton, Taylor and Francis Group; London

30. Ariweriokuma SV, Akinrotimi OA, Gabriel UU (2011) Effects of cypermethrin on condition factor and organosomatic indices of Clarias gariepinus. Agric Social Res 11:67-72

31. Atef NM, Shanab SM, Negm SI, Abbas YA (2019) Evaluation of antimicrobial activity of some plant extracts against antibiotic susceptible and resistant bacterial strains causing wound infection. Bull Natl Res Cent 43:144

32. Ribeiro OIC, Mariano EGA, Careli RT, Morais-Costa F, de Sant'Anna FM, Pinto MS, de Souza MR, Duarte ER, (2018) Plants of the Cerrado with antimicrobial effects against Staphylococcus spp. and Escherichia coli from cattle. BMC Vet Res 14:32

33. Bereksi MS, Hassaïne $H$, Bekhechi C, Abdelouahid DE (2018) Evaluation of antibacterial activity of some medicinal plants extracts commonly used in Algerian traditional medicine against some pathogenic bacteria. Pharmacog J 10:507-512

34. Nkala BA, Mbongwa HP, Owebani-Ogunleye T (2019) The in vitro evaluation of some South African plant extracts for minimum inhibition concentration and minimum bactericidal concentration against selected bacterial strains. IJSRP 9:996-1004

35. Oskay M, Oskay D, Kalyoncu F (2009) Activity of some plant extracts of some plant extracts some plant extracts plant extracts extracts against multi-drug resistant human pathogens-drug resistant human pathogens. IJPR 8:293-300 
36. Waithaka PN, Gathuru EM, Githaiga BM, Kazungu RZ (2018) Antimicrobial Properties of Aloe vera, Aloe volkensii and Aloe secundiflora from Egerton University. Acta Scientif Microbiol 1:06-10

37. Ginovyan M, Petrosyan M, Trchounian A (2017) Antimicrobial activity of some plantmaterials used in Armenian traditional medicine. BMC Compl Alt Med 17:50

\section{Publisher's Note}

Springer Nature remains neutral with regard to jurisdictional claims in published maps and institutional affiliations.
Submit your manuscript to a SpringerOpen ${ }^{0}$ journal and benefit from:

- Convenient online submission

- Rigorous peer review

- Open access: articles freely available online

- High visibility within the field

- Retaining the copyright to your article

Submit your next manuscript at $\boldsymbol{\nabla}$ springeropen.com 